\title{
"Reader, I Detained Him Under the Mental Health Act": A Literary Response to Professor Fennell's Best Interests and Treatment for Mental Disorder
}

\author{
David Gurnham
}

Published online: 19 July 2008

(C) The Author(s) 2008

\begin{abstract}
This is a response to Professor Fennell's paper on the recent influence and impact of the best interests test on the treatment of patients detained under the Mental Health Act 1983 (MHA) for mental disorder. I discuss two points of general ethical significance raised by Professor Fennell. Firstly, I consider his argument on the breadth of the best interests test, incorporating as it does factors considerably wider than those of medical justifications and the risk of harm. Secondly, I discuss his contention that the apparent permeability of the line between the interests of the patient and the interests of society is something to be concerned about in itself. Since the overarching theme of the paper is the proper place of social and cultural values, my reponse considers the implications of Fennell's arguments in the light of Charlotte Brontë's novel 'Jane Eyre', which, through the character of Bertha Mason (the infamous 'mad woman in the attic') provides a provocative study of the relationship between mental disorder and society.
\end{abstract}

Keywords Mental Health Act · Mental Capacity Act · Mental disorder · Best interests · Consent · Treatment

\section{Introduction}

For evidence that the best interests test and the paternalism that underpins it-once the undisputed king of medical decision-making - is now thoroughly unfashionable, one need only look at the Mental Capacity Act 2005 (MCA). The legislation is socalled in order to present itself in alignment with currently much more favourable principles such as autonomy, even though it deals largely with patients' incapacity

\footnotetext{
D. Gurnham $(\bowtie)$

Centre for Social Ethics and Policy, School of Law, University of Manchester,

Oxford Road, Manchester M13 9PL, UK

e-mail: David.gurnham@Manchester.ac.uk
} 
in medical decision-making. On the best interests test itself the statute also goes out of its way to formulate the test in such a way as to promote autonomy as far as possible, reminding medical practitioners that patients who struggle to understand, retain, weigh and use a doctor's advice (who would formerly have been assumed to be straightforwardly incompetent) are not the mute subjects of King best interests, but citizens within a participatory democracy. Patients themselves are given a role in the best interests assessment, both in fact where possible and through a watered down form of substituted judgment where it is not. Professor Fennell's paper traces the line in English law on treating mental health patients that, at least formally, separates the broad best interests test for incompetent patients under MCA 2005 and the tests for the detention and treatment of patients without their consent who pose a risk to self and/or others for 'mental disorder' under the Mental Health Act 1983 and 2007 (MHA): to come into force October 2008. Although the MCA is explicitly excluded from consideration when a patient is detained under the MHA, it has somehow got in through the back door. Professor Fennell argues that best interests reasoning has widened an already worryingly broad range of reasons for justifying treating patients treated for mental disorder, increasing the decision-making power for the medical practitioner over the patient. In this response piece I would like to focus upon two lines of thought that may be developed from Professor Fennell's paper. The first is the question of the interpretation of the legal test for justified treatment without consent under the MHA and the extent to which best interests reasoning makes a positive or negative contribution. The second is the role of the medical practitioner him/herself in relation to exercising decision-making powers under the law and the strength of Professor Fennell's criticism that the best interests test unjustly allows the practitioner's own social and cultural values to determine their decisions. Imposing something of my own social and cultural attitudes on this discussion, I shall illustrate my own response with reference to Charlotte Brontë's Jane Eyre.

\section{The (un)Welcome Presence of Best Interests and the Meaning of 'Appropriate'}

Part IV of the MHA 1983 provides that treatments may be given without the detained patient's consent, whether in emergency situations (s.62) or other types of situation for mental disorder, some of which require a second opinion (s.58) and others that do not (s.63), in order to safeguard the life or health of that patient, or that of others. Professor Fennell worries that in the instance of s.63 at least, decided case-law shows that, far from merely allowing routine and strictly necessary activity of mental health practitioners to take place without unnecessary legal impediment, the MHA has been, and will increasingly be, interpreted to justify treatment in terms so broad as to cause concern. In all cases, the test to be applied under the MHA is that the proposed treatment will 'alleviate or prevent deterioration in the patient's condition'. However, in fleshing out this notion, the courts seem to have become dissatisfied with considering this question as separate to that of the patient's best interests-i.e. reasoning imported from the explicitly excluded MCA. For Professor Fennell, since 'best interests' is itself so broad a concept, courts' increasing acceptance of the 
relevance of the best interests test will allow medical practitioners to justify treatment in the interests of society-a troublingly vague basis on which to make so serious a decision for the patient in question. Two cases that point to this convergence of the MHA and MCA are Tameside and Glossop Acute Services Trust $v$ $\mathrm{CH}^{1}$ (use of reasonable force on a schizophrenic woman to secure delivery of her baby by caesarean section) and $R$ (on the application of $N$ ) $v \operatorname{Dr} M^{2}$ (obligation to consider patient's best interests as well as medical necessity in approving treatment).

The relevance of these cases here is the extent to which best interests reasoning can or should be distinguished from that of medical necessity under the MHA. The formal legal division becomes clearer when we consider cases that fall under the scope of best interests. There is a long and now familiar and largely uncontroversial line of case-law that is usually traced to the House of Lords decision of $\operatorname{Re} F$ (adult sterilisation $)^{3}$ that underscores the position that an incompetent patient may be treated without their consent in their best interests, a procedure now codified in the MCA. These judgments are authoritative in the case of patients who are not detained under the MHA. To be treated in one's best interests under the MCA, a patient does not have to be suffering from a 'mental disorder' as it is defined under s.1(2) of the MHA, ${ }^{4}$ but from any 'mental disability' which prevents them from taking the relevant decision for themselves. According to Professor Fennell, the fact that 'best interests' reasoning has 'become relevant' to MHA cases also, 'serves to extend clinical discretion which is already wide as a result of the broad definition of treatment for mental disorder, by extending beyond the medical the range of interests which may be served by treatment without consent'. 5 As a bald fact, this must be true: the Court of Appeal has often stressed that best interests incorporates considerations far wider than the medical. Lord Justices have taken a balance sheet approach to assessing best interests, and the 'balancing exercise' of benefits and burdens which may incorporate considerations of the patient's health, welfare, emotional needs, family arrangements and care provisions, etc. ${ }^{6}$ The implication is that, unlike the supposedly stricter confines of the MHA, there is nothing particularly ruled out of consideration in an assessment of a patient's best interests. Is there a good reason for seeking to exclude best interests from MHA cases? For Professor Fennell, this is a question of the breadth of power to be handed to the

\footnotetext{
${ }^{1}$ [1996] 1 FLR 762, FD.

2 [2002] EWCA Civ 1789.

3 [1990] 2 AC 1.

4 s.1(2): “Mental disorder' means mental illness, arrested or incomplete development of mind, psychopathic disorder and any other disorder or disability of mind.' The Mental Health Act 2007 will replace this definition (from October 2008) with this rather more general phrase: “mental disorder' means any disorder or disability of the mind'.

5 P. Fennell, 'Best Interests and Treatment for Mental Disorder' in this issue. Due to editorial and printing restrictions beyond the author's control, references to Professor Fennell's paper do not specify page numbers.

${ }^{6}$ See, for example, $\operatorname{Re} S$ (Adult Patient: Sterilisation) [2001] Fam 15, in which Thorpe LJ stated that the test 'embraces issues far wider than the medical' (30) and Dame Butler-Sloss P that it incorporated 'broader ethical, social moral and welfare considerations' (27). The latter has also ruled that best interests is to be 'interpreted more broadly than 'medical interests' and include emotional and other factors' $\operatorname{Re} L$ (Medical Treatment: Benefit) [2004] EWHC 2713 (Fam) para [12].
} 
mental health practitioner. After all, in H.L. $v U K^{7}$ (the 'Bournewood' decision) the European Court of Human Rights drew a clear distinction between the two legal frameworks in terms of the treatment of patients and limitations on carers and medical practitioners. If the requirement that a patient must be 'detained' before non-consensual treatment for mental disorder may be administered is to be practically effective, surely it should provide some protection for patients from the much wider best interests test?

What are we to make of the observation that the best interests test incorporates wider social interests as well as the patients' own best interests? I think that this observation needs to be read in conjunction with related comments made at various points in Fennell's paper on the breadth of discretion open to mental health practitioners. On the MHA case of $\mathrm{CH}^{8}$ Professor Fennell writes: 'This case stretched the concept of treatment for mental disorder to the very limit. It also revealed the permeability of the boundary between best interests of the patient and the interests of others'. 9 This seems to imply that case-law has allowed the MHA to be interpreted so widely that a line has been brought into view-at which the actions of mental health practitioners could no longer be regarded as 'treatment for mental disorder' - which should not be crossed. On the 'balance-sheet' character of the best interests test applied in the courts, Professor Fennell states: 'Although preferable to Bolam, the balance-sheet approach with its broad range of interests that may be taken into account, still leaves considerable discretion with clinicians'. ${ }^{10}$ And, why is the balance sheet approach to be preferred to the Bolam principle (that a decision should not be deemed unlawful if a responsible body of medical opinion would support the decision in question)? Although Professor Fennell does not make it explicitly clear, the answer seems to lie in the breadth of discretion conferred by Bolam. For instance, at an earlier point in the paper, Professor Fennell argues that the 'Bolam principle effectively confers great discretion on clinicians to decide what treatment may appropriately be given, and its use in guidance to Second Opinion Appointed Doctors (SOADs) has ensured that a treatment proposal will be denied approval only in the rarest of circumstances, and that approval is granted to treatment without significant change in $98 \%$ of cases'. ${ }^{11}$ Does Professor Fennell mean to say therefore that the balance sheet of benefits and burdens of a course of action considered in the best interests test is preferable to the Bolam principle since it provides a means for imposing stricter controls on such decisions? The answer is unclear, especially since ${ }^{12}$ Professor Fennell seems also to suggest that it is the best interests test and not the Bolam principle that confers the wider discretion on mental health practitioners: "Best interests' has become relevant to decision-making under Part IV of the MHA 1983, but it serves to extend clinical discretion which is already wide as a result of the broad definition of treatment for mental disorder...' At no

\footnotetext{
7 [2004] ECHR 45508/99.

8 See note 1 above.

9 Fennell, op cit.

${ }^{10}$ Fennell, op cit.

11 Fennell, op cit.

12 Fennell, op cit.
} 
point in his paper does Professor Fennell suggest that the best interests test ought actually to be excluded from MHA reasoning. In any case, as Professor Fennell states ${ }^{13}$ to rely solely on the Bolam principle to the exclusion of other considerations (of which the best interests test may be one) in MHA detention and treatment cases may be incompatible with the Human Rights Act 1998 (HRA). In other words, under the HRA, for the MHA to be compatible with patients' Convention rights under Article 3 (torture and degrading treatment) and Article 8 (individual autonomy of personal decisions), the best interests test as it is formulated in MCA with its emphasis on the involvement of the patient whenever possible means that best interests would risk violation of these provisions. Best interests reasoning may therefore have a legitimate place in MHA reasoning, but Fennell's references to the 'expansive approach' ${ }^{14}$ of the best interests test implies that what he finds troubling is the breadth of the discretion itself, and that there are no effective limitations on clinical discretion. As he concludes 'In order to comply with the European Convention the tests of clinical necessity and best interests will have to be applied, but as we have seen these do not represent a significant limitation on clinical discretion'. ${ }^{15}$ Fennell does not argue strongly either for restricting the expansive discretion he identifies in the MHA case-law or in its defence. The most that I feel I can say is that it is commented upon as a potential concern, possibly as a basis for future critique.

Whatever the truth of Professor Fennell's own feelings, my own view is that there is no reason to suppose that consideration of the much wider social interests would be more likely than not to be antagonistic or injurious to the patient's own medical interests. I think that in order adequately to uphold patients' Convention rights, medical practitioners and courts do need to have access to an interpretive framework that is wider than merely medical or risk based. The English courts have not yet held that any part of the MHA permits the treatment for a mental disorder without consent simply because it is in the best interests of patients or others. However, the consideration of the patient's best interests are surely highly relevant to deciding the narrower question as to medical necessity. Fennell argues that the case of $\mathrm{CH}$ illustrates the "permeability of the boundary between the best interests of the patient and the interests of others' ${ }^{16}$ It is true that the treatment was given firstly in order to ensure the safe delivery of the fetus rather than to prevent direct harm to the patient. However, the Court of Appeal were also careful to emphasise that the treatment given was necessary to prevent the worsening of her schizophrenia, which is clearly appropriate to MHA reasoning. The new criteria for $\mathrm{s} .58$ treatments under the new MHA 2007-that of 'appropriateness'-is, as Professor Fennell states, apparently much wider than the 1983 requirement, especially as it is defined in the new legislation somewhat tautologically as treatment that is 'appropriate in his case, taking into account the nature and degree of the mental disorder and all other

\footnotetext{
${ }^{13}$ Fennell, op cit.

14 Fennell, op cit.

15 Fennell, op cit.

16 Fennell, op cit.
} 
circumstances of his case'. ${ }^{17}$ The very general justification for s.58 treatment does seem to be an invitation for best-interests-type reasoning, and so the vast body of existing best interests case-law in the Court of Appeal will be a helpful interpretive tool.

It is in the context of establishing when treatment is 'appropriate' that the involvement of best interests may be challenged. Can it be that the best interests is a test of bad faith, in the Satrean sense of diverting one's mind from the true purpose of one's behaviour? The next section of this response paper deals more fully with the social and cultural aspects of this question. For now, however, it may be helpful briefly to consider here the ethical import of the MHA 2007's use of such an expression as 'appropriate', and the relevance of the very broad social best interests test that worries Professor Fennell. Mental health and particularly individuals with mental health problems are a source of some considerable anxiety for policy makers and also those who comment on policy in this area. In Charlotte Brontë's Jane Eyre, first published in London in 1847, the passionate and brooding Mr Rochester finally confesses that he has for ten years kept his mentally ill wife, Bertha Mason, locked away in the attic of his stately home of Thornfield. Rochester explains how, as a rash youth, he was misled into the arranged marriage with a 'tall, dark and majestic' ${ }^{18}$ Creole woman by a collusion of friends and family who concealed her true nature from him before the wedding. After a few years of miserable marriage in the West Indies in which Rochester quickly finds her to be completely unsuitable as a wife-'her nature wholly alien to mine, her tastes obnoxious to me, her cast of mind common, low, narrow and singularly incapable of being led to anything higher, expanded to anything larger' (269)—-he decides on a course of action that he explains as done in her own best interests - as appropriate in the full context of her mental condition. The marriage and subsequent concealment is discovered by Jane to the latter's horror. In a crucial scene in which we discover the impressive strength of Jane Eyre's commitment to social and legal norms, Rochester attempts to justify his actions thus:

'Go', said Hope, 'and live in Europe. ... You may take the maniac with you to England; confine her with due attendance and precautions at Thornfield. ... See that she is cared for as her condition demands, and you have done all that God and humanity require of you. ... Place her in safety and comfort: shelter her degradation with secrecy, and leave her.' (271-2, abbreviated)

In other words, Rochester treated Bertha's condition with forced confinement and concealment from all of society apart from Grace Poole (employed by Rochester to take care of her needs) in her own best interests. However, Rochester's view of best interests is not limited to the interests of the individual. There are of course his own personal interests - 'I have a right to deliver myself from it if I can. ...- - let me break away, and go home to God!' (271)—and one also gets the impression that he feels that his attempted bigamy notwithstanding, he has acted as a representative of civilised society as a whole. Far away from home in the West Indies, he feels 'the

\footnotetext{
17 Mental Health Act 2007, s.4(3)(4).

18 Charlotte Brontë, Jane Eyre, Richard J. Dunn (ed.) (London and New York: Norton, 1971) p. 268.
} 
sweet wind from Europe... whispering in the refreshed leaves', and he ascribes his clarity of thought to Wisdom itself, 'for it was true Wisdom that consoled me in that hour, and showed me the right path to follow.' (271) This is what makes his decision to shut Bertha away forever 'appropriate' in a broader sense.

These passages from Jane Eyre give us some idea of what the ethical significance might be of Professor Fennell's remarking on the 'permeability' of the boundary between the interests of the patient and the interests of society in MHA case-law. ${ }^{19}$ In terms of deciding in the interests of the patient alone, the best interests test may be a test of bad faith, since whilst it helps us to be assured (or 'feelgood', as Professor Fennell puts $i^{20}$ ) that any treatment given coercively to a non-consenting patient for a mental disorder is indeed 'appropriate' for the patient, it leaves open the risk that it may be much more appropriate for society as a whole. The interpretation of the meaning of Bertha Mason's violence towards herself (she eventually throws herself from a window in chapter 36) and to others (she tries to throttle and bite Mr Rochester in chapter 26) cannot exclude social and cultural values. The incorporation of the word 'appropriate' into the test for treatment under the new legislation is an invitation to critically reflect on the role of social constructions of best interests. Ethical critique of the recent case-law and future developments of mental health policy should be directed not towards the exclusion of cultural and social aspects of the best interests test, but rather to finding a positive and mutually complementary place for them.

\section{The Social and Cultural Values of the Decision-Maker}

Professor Fennell associates best interests with other concepts capable of affording divergent meanings. Human dignity, as Fennell points out in the quotation below, is also invoked without the content of the expression being known or knowable in advance. Rather, it conveys a feeling that the right thing is being done:

Although 'best interests' invokes a 'feelgood' response almost on a par with the related concept of human dignity, decisions on these questions are profoundly influenced by the social and cultural values of the decision-maker. Each idea is capable of justifying divergent conclusion as to what outcome upholds dignity or best interests. $^{21}$

The idea of best interests also shares with human dignity an objective perspective on what is best for the patient which, in paternalistically displacing the actual or presumed views of the patient, has the potential for violence. As objective concepts, both may be (and are) invoked in medical and criminal law to protect a person from their own self-destructive wishes. Of course, as Professor Fennell argues, decisions made in a patient's best interests are not really objective as such (or rather, few would believe them to be so), but the decision-maker's own professional judgment,

\footnotetext{
19 P. Fennell, op cit.

${ }^{20}$ Fennell, op cit.

21 Fennell, op cit.
} 
and since different mental health practitioners will differ on their interpretations, 'best interests' decisions will vary according to the decision-maker's personal attitudes. The MCA goes into some depth in stipulating how the best interests of a patient are to be determined: who to ask, what aspects of the patient's family and personal life to take into account, etc. However, the statute does not define best interests itself, as what is in any given patient's best interests is dependent upon the precise circumstances of his predicament. It must be true that this leaves some considerable scope for interpretation by the medical decision-maker. Again, Fennell does not make himself explicitly clear on critical implications of the relationship he identifies between the 'feelgood' response' (i.e. claiming universal approval) invoked by best interests and the room that this makes for the 'profound influence' of a decision-maker's 'social and cultural values'. However, given my earlier interpretation of his comments on the best interests test as critical as opposed to merely descriptive of the 'expansive approach' of the best interests balance sheet approach, I cannot read this statement without reading into it an implied suggestion that the opportunity for, as Professor Fennell puts it in the very last line of his paper, 'justifying a broad range of compulsory interventions in the name of treatment for mental disorder ${ }^{22}$ is a reason at least to be a little worried about it.

However, as I think Professor Fennell would accept, this can only be the very start of a critique of the law. The mere fact that assessments of best interests are 'profoundly influenced by the social and cultural values of the decision-maker' cannot in itself be grounds for critique, and nor do I think Professor Fennell wants to suggest otherwise. Professor Fennell has demonstrated in his paper that the very definition of mental disorder is itself open to social and cultural interpretation, depending on the risk of a mental condition to manifest in violence and physical harm. Criminal lawyers have long been acutely aware of the difficulties that law's concern to limit and control violent behaviour has posed for the relationship between law and mental health. For example, a finding that a defendant was insane when he committed an act of violence allows the court to order indefinite detention in a secure mental hospital. Lord Denning's well-known definition of a 'disease of the mind' for the purposes of the insanity defence is generally accepted as having very little to do with medicine as such: 'any mental disorder which has manifested itself in violence and is prone to recur is a disease of the mind' ${ }^{23}$ The reason why Lord Denning's definition survives is because it is recognised that, although medically meaningless, it serves the law's purpose - that of controlling violence and physical harm. Professor Fennell has similarly shown how certain cases on detention and treatment under the MHA have 'stretched the concept of treatment for mental disorder to the very limit', adopting a flexible approach to mental disorder in order to allow medical practitioners to perform operations and treatments they think necessary. But if the raison d'etre of the mental health legislation is to deal with violent or harmful individuals, the limit of treatment for mental disorder will be determined, not by medically defendable definitions of mental disorder as such, but by prosaic legal imperatives. To borrow from the vocabulary of human rights

\footnotetext{
${ }^{22}$ Fennell, op cit.

${ }^{23}$ Bratty v A-G for Northern Ireland [1963] AC 386 at 410.
} 
lawyers, permitting the consideration of 'social and cultural values' to enter the frame in mental health might be described as a legitimate aim in controlling the risk of harm that stems from abnormal behaviour stemming from mental disorder.

What should attract the attention of law's critics therefore, is not the fact that decision-makers are influenced by social and cultural values, but rather the law's claim to be legitimately pursuing the aim of controlling violence manifests itself in particular cases and the implications this has for principles of medical ethics, such as the rights of the patient. If decision-makers are permitted to treat without consent without specific risks of harm being identified, the claim to be pursuing a particular necessary end starts to look weaker. In Professor Fennell's paper, the case of $\mathrm{CH}$, cited above, is one such example, since although there was evidence of a risk of harm to the pregnant patient as a result of her schizophrenia, it is unlikely that the force used to deliver her baby by caesarean section would have been thought necessary had the decision-maker not brought particular social and cultural attitudes towards fetal welfare to the issue. Charlotte Brontë's depiction of an instance of mental health 'treatment' in the nineteenth century also gives us an opportunity to reflect on the ethical implications of defining mental disorder according to social and cultural values. In support of his view that Bertha Mason was a 'lunatic' requiring incarceration, Mr Rochester says:

$[\mathrm{H}]$ er vices sprang up fast and rank: they were so strong, only cruelty could check them, and I would not use cruelty. What a pigmy intellect she had, and what giant propensities! How fearful were the curses those propensities entailed on me! Bertha Mason, the true daughter of an infamous mother, dragged me though all the hideous and degrading agonies which must attend a man bound to a wife at once intemperate and unchaste. (269-70)

Mr Rochester is no medical expert, but as a gentleman in nineteenth century England and a man of the world [he has travelled across the world and lived, 'sometimes in St Petersburg, oftener in Paris; occasionally in Rome, Naples and Florence' (273)] he is an authority on what is acceptable and what is unacceptable behaviour for a society lady. Mr Rochester finds that Bertha Mason's madness stems from a mental disorder inherited from her 'infamous mother', but from the perspective of a reader outside of nineteenth century society it looks as if the rage and fury that Bertha displays later in life arise instead from a lifetime of being imprisoned for her refusal to conform to patriarchal notions of an obedient, wellmannered and faithful wife. This is not the place for detailed psychological analysis, nor for a discussion of the gender-political questions of power and control of women or difference. However, what is important to note for this discussion on the role of 'best interests', is that when Mr Rochester decided that the drastic action of shutting her away was necessary, it seems to have been a decision-based as much on social and cultural factors as psychological ones. He complains of the injury her 'impure, depraved' character did to his self-respect and social standing: 'society associated my name and person with hers' (270). He complains that 'no professed harlot ever had a fouler vocabulary than she', and that her 'wolfish cries' (presumably in protest at having been shut up) woke him at night (271). 
Professor Fennell does not develop his own views on the extent of the possible implications of his cautionary note about the incorporation of social and cultural values into MHA decisions. But there is certainly an ethical question to be posed here. If there really is, as Fennell implies, a blurring of the line between social/ cultural values and the medical question of risks and harms, could modern patients be vulnerable the kind of violation of liberty portrayed by Charlotte Brontë? I have interpreted Professor Fennel to have suggested in his paper that the nature of best interests as a 'feelgood' or 'portmanteau' concept means that we have cause to worry about the kinds of decisions-socially and culturally diverse as they consequently are-that mental health practitioners make for patients. If there is indeed cause for concern about this, it is necessary to take a critical view of the kinds of social and cultural values that inform and influence decision-making, and the way in which this takes place. Reading literature is one way of developing such a critical attitude to decision-making processes. For instance, the depiction of the treatment of mental disorder in Jane Eyre must be read in the context of prevailing attitudes towards mental illness and patients' rights in the nineteenth century, in which medical paternalism really was king. Mr Rochester's treatment of Bertha Mason reflects, not just the idiosyncratic views of one character, but an historically specific attitude towards mental health and mental disorder. Therefore, what is significant is not that individual medical practitioners should be prevented from making detention and treatment decisions in the light of their own social and cultural values, but that the legal framework itself reflects a set of values that are sound guiding principles for decision-making. Although today's best interests test is undoubtedly paternalistic, it is only fair to acknowledge that modern medical and legal culture gives a more central role to the patient than previous conceptions of the test. If best interests reasoning is to become formally incorporated into MHA decision-making, then it is possible that the MCA's emphasis on elements of substituted judgment (the patient's past and present wishes, feelings and beliefs) and measures that medical practitioners are obliged to undertake to encourage patients as far as possible to be involved in best interests assessments, means that while it is always possible for broader social and cultural factors to affect the decision as to whether to treat, patient-centred, autonomy-based values will also exert a countervailing influence.

\section{Conclusion}

It is quite possible that the trend towards convergence of the tests for treatment without consent under the MHA and treatment of incompetent patients in their best interests will continue, especially given the pre-eminence of Convention rights since the HRA 1998 came into force. Whether or not we will see a formal collapse of the legal distinction between detention under MHA and treatment in a patient's best interests under MCA may depend significantly upon developments in the legal definition of competence. Under the MHA, a detained individual may be treated without their consent even if they would not be judged incompetent under s. 3 of the MCA, whereas in the case of patients who are not detained, patients' own consent is 
necessary unless they are judged incompetent to decide for themselves. Professor Fennell warns that the increasing permeability of the boundary between these two different legal frameworks allows for a greater range of justifications for treating patients without their consent, and thus greater power to the medical decisionmakers to exercise paternalistic judgements and impose their own values and beliefs. In response, I have argued firstly that the incorporation of the broader best interests reasoning may be necessary to protect patients' Convention rights and secondly that in our critical engagement with treatment decisions it is the social and cultural values promoted in the legal sources that should concern us more than the individual beliefs of medical practitioners. The moves towards recognising the importance of a patient-centred approach to best interests (as evidenced by the MCA) provides some cause for optimism.

Open Access This article is distributed under the terms of the Creative Commons Attribution Noncommercial License which permits any noncommercial use, distribution, and reproduction in any medium, provided the original author(s) and source are credited. 